\title{
Ginger Tea on Dysmenorrhoea Among Nursing Students
}

\author{
Sheetal Crasta ${ }^{1}$ Philomena Fernandes ${ }^{2}$ Shynee Paul ${ }^{2}$ \\ ${ }^{1}$ Prime Medical Center, Dubai, United Arab Emirates \\ ${ }^{2}$ Nitte Usha Institute of Nursing Sciences, Mangaluru, Karnataka, \\ India \\ Address for correspondence Philomena Fernandes, MSc (Nursing), \\ Nitte Usha Institute of Nursing Sciences, Deralakatte, Mangaluru, \\ Karnataka, India (e-mail: philomena@nitte.edu.in).
}

J Health Allied Sci Nu 2019;9:64-75

\begin{abstract}
Background Dysmenorrhea is a common problem which can alter the daily routines of females. Primary dysmenorrhea affects 40 to $90 \%$ women. Dysmenorrhea sufferers account for 3 among 4 women as per evidences. Traditional remedies are chosen to get some relief because of their least side effects. These remedies have a favorable effect in reducing dysmenorrhea. Ginger is used since ancient times as various forms of alternative medicine. One of the traditional uses of ginger is for pain relief, including menstrual pain. The aim of this study was to identify the effectiveness of ginger tea in dysmenorrhea.

Objectives The objectives of this study are (1) Assess the level of dysmenorrhea among nursing students. (2) Determine the effectiveness of ginger tea on dysmenorrhea among nursing students. (3) Find the association between level of dysmenorrhea before the administration of ginger tea and demographic variables.

Methodology A quantitative research approach with quasi-experimental design was considered. The sample comprised of 50 students with moderate and severe menstrual pain as per numerical pain rating scale. The baseline data was collected. Ginger tea was prepared by the researcher and administered $120 \mathrm{~mL}$ to the subjects; on the first 2 days of menstruation in the morning and night after breakfast and dinner, respectively. Level of different aspects of pain was assessed before the administration as well as 2 hours after administration of ginger tea using Pain Quality Assessment Scale. Pre- and post-test were taken before as well as 2 hours after administering the drink. A total of four doses are given and ratings were measured eight times. Data was analyzed using descriptive and inferential statistics.

Results The present study revealed that the median score of all seven characteristics of pain was higher in the preintervention when compared with postintervention. MannWhitney $U$ test showed that there was a significant difference in level of pain between the experimental and control groups $(p<0.05)$. Wilcoxon signed-rank test showed that

Keywords

- ginger tea

- effectiveness

- dysmenorrhea

- nursing students there was a significant difference in pain measurements before and after the administration of ginger tea $(p<0.05)$. These findings indicate that ginger tea was effective in reducing menstrual pain. Chi-square test and likelihood ratio were used to find the association between baseline dysmenorrhea with demographic and clinical variables. It was found that there is no significant association $(p>0.05)$. The responses given by
\end{abstract}

received

August 1, 2019

accepted after revision

September 5, 2019
DOI https://doi.org/

$10.1055 / \mathrm{s}-0039-1700705$
Copyright @2019 Nitte University

(Deemed to be University)
License terms

(우 (1) $\ominus \circledast$ 
the experimental and control group was mentioned separately. Ginger tea effects and experience were verbalized by the experimental group alone. This supported the statistical finding that ginger tea is effective in reducing dysmenorrhea.

Conclusion Findings revealed that the administration of ginger tea can bring a sudden relief among the subjects with dysmenorrhea. The awareness about alternative therapies must be created among public.

\section{Introduction}

In India, woman is considered as a weaker section of the society. The physical makeup of a woman has also contributed in underestimating a woman. The pain and associated symptoms a woman experiences during her periods are one of the common problems experienced by many adolescent girls.

Dysmenorrhea affects the quality of life of women especially of those who are working and studying. One in 13 sufferers is incapacitated for 1 to 3 days per month, affecting work and school attendance and making dysmenorrhea the leading cause of school absenteeism among adolescents. Symptoms may differ in each individual: it includes dizziness and syncope, cramping, nausea, vomiting, diarrhea, headaches, and fatigue; and may last up to 72 hours. ${ }^{3}$

Women begin to depend on medications as a solution for this problem. Because of the drastic physical growth that occurs during adolescence, most of them do not want to depend solely on pharmacologic treatments. ${ }^{1}$

Alternative therapies have gained importance in this context. There are many home remedies known to get relief from primary dysmenorrhea (PD). Some of them are dietary modifications, heat application, yoga, exercises, herbs. Numerous researches are being performed which focuses on complementary and alternative interventions for dysmenorrhea. This includes the use of muscle relaxation therapy, magnetic therapy, reflexology, hand acupuncture, aroma therapy, acupressure, etc. In one large study, as many as $48 \%$ of women reported use of complementary and alternative medicine as an alternative to prescription medication or to enhance the effectiveness of their prescription medications. ${ }^{2,3}$

Ginger is the world's most gifted, evidence-based natural health remedy. Ayurvedic texts consider ginger as the queen of herbs available, as it is a complete medicine molded in itself. Ginger contains "gingerol," which is a highly potent anti- inflammatory compound responsible for alleviating joint and muscle pain. Ginger helps women effectively reduce the pain associated with dysmenorrhea. A research study in Iran divided 70 female students into two groups. One group was administered ginger capsules and the other was given a placebo-each for the first 3 days of their menstrual cycles. The researchers found that $82.85 \%$ of the women taking ginger capsules reported improvements in pain symptoms, compared with $47.05 \%$ of those on placebo. ${ }^{4}$

\section{Background}

Menarche is the attainment of womanhood. In the Indian scenario, it is a significant event which determines a girl's maturity and labels her fit for marriage. There are many physiological and psychological changes happening to a girl during menstruation. Pain, fatigue, nausea, vomiting, anxiety, depression, cramps, etc. are experienced during menstruation. ${ }^{5}$

Painful menstruation without any pathologic conditions is called dysmenorrhea. One in every two women who have their periods suffers from dysmenorrhea, or intense pain and cramping during menstruation. ${ }^{6}$ There are two types of dysmenorrhea: primary and secondary. PD is characterized by painful menstrual cramps without any evident pathology. ${ }^{7}$ Secondary dysmenorrhea is the occurrence of painful menstruation in the presence of a pelvic pathology, such as endometriosis, adenomyosis, or chronic pelvic inflammatory disease. $^{8}$

PD is seen in women of all ages but usually begins at adolescence, with an estimated prevalence of 40 to $50 \% .^{7}$ PD typically begins in the adolescent years roughly 6 to 12 months after menarche, usually with the establishment regular ovulatory cycles. ${ }^{9}$ Overall, PD may affect 40 to $90 \%$ of women. ${ }^{10}$

$\mathrm{PD}$ is seen in 3 out of 4 women. One in 4 women with dysmenorrhea has a secondary form caused by an underlying gynecological condition. In an estimate, 5 to $15 \%$ of women with PD suffer from pain that hinders their general routines. ${ }^{11}$ In a study conducted among students attending college, at Indore city of central India, dysmenorrhea was reported in $84.2 \%$ (261) girls, and $15.8 \%$ (49) reported no dysmenorrhea of which $34.2 \%$ of girls experienced severe pain, $36.6 \%$ moderate pain, and $29.2 \%$ had mild pain. ${ }^{6}$

PD occurs in the absence of anatomic abnormalities or pelvic pathologic disorders in which pain begins at the onset of the menstrual flow and lasts for 12 to 48 hours. PD is the occurrence of a physiologic alteration and it usually appears 6 to 12 months after menarche, when ovulation is established. Secondary dysmenorrhea is acquired menstrual pain that develops after 25 years. It is associated with pathologic disorders. ${ }^{12}$

Traditional remedies are gaining dominance over the pharmacological management due to its least side effects. Home remedies for dysmenorrhea include regular exercise, yoga, and consumption of mint, ginger, parsley, basil, 
cinnamon, asafetida, and aloe vera. Eating a wholesome diet on a regular basis that includes proteins, vitamins, minerals, and antioxidants is also a good home remedy. These home remedies have a direct and positive effect on dysmenorrhea and help curing the causes without adverse side effects. ${ }^{13}$

Ginger is one among the healthiest (and most delicious) spices on the planet. It is nourished with nutrient compounds that have powerful benefits for the body and brain. Ginger has a very long history of use in various forms of traditional/ alternative medicine. It aids in digestion, reduce nausea, and help to treat flu and common cold. One of the traditional uses of ginger is for pain relief, including menstrual pain. ${ }^{14}$

\section{Need for the Study}

Dysmenorrhea is a common problem affecting majority of women. Pain during menstruation or dysmenorrhea occurs in $50 \%$ of menstruating women and approximately $10 \%$ are incapacitated for 1 to 3 days each month. In the first year after menarche, $38 \%$ of girls develop dysmenorrhea, and in the second and third year after menarche, 20\% experience pain related to menstruation. About $80 \%$ of women who develop dysmenorrhea do so within 3 years of menarche. Over the age of 25 years the cause of dysmenorrhea is usually secondary to other pelvic problems. ${ }^{15}$

Adolescents consulting for dysmenorrhea are very few and they prefer over-the-counter medicines or home remedies. Therefore, statistics about prevalence of menstrual problems or dysmenorrhea and their causes are poorly available due to underreporting. Recently, it has become an important public health problem among the female population; prevalence rate reported from different regions of India appears to be as follows: Delhi $63.75 \%{ }^{16}$ and Chennai $61 \%{ }^{17}$ in certain regions, prevalence rate is reported to be as high as 71 to $93 \%$; difference can be attributed to region-specific environment, age of participants, and study protocol. ${ }^{18}$

A study conducted in Western Turkey to evaluate the prevalence of dysmenorrhea and determine its effect on health-related quality of life among a group of female university students revealed that dysmenorrhea is a common health problem, having negative effects on the health-related quality among university female students. The study also found a high prevalence of dysmenorrhea (72.7\%) being reported among female students. ${ }^{19}$

It is the responsibility of health care professionals to create awareness among the female population regarding the common reproductive diseases and its available remedies. Dysmenorrhea has many nonpharmacological interventions among which ginger is one which has proved to be effective in various studies. According to modern scientific researches, ginger possesses numerous therapeutic properties including antioxidant effects, an ability to inhibit the formation of inflammatory compounds, and direct antiinflammatory effects. One theory believes that increased prostaglandin levels produce increased myometrial contractility, uterine ischemia, and sensitization of pain fibers, which lead to pelvic pain. Women with PD have higher levels of endometrial prostaglandins F2-a and E2 and leukotrienes than non-dysmenorrheic women. ${ }^{20}$

A systematic review done in U.S. evaluates the current evidence for the effectiveness of ginger for treating PD and the study concluded by proving the evidence for the effectiveness of 750 to $2,000 \mathrm{mg}$ ginger powder during the first 3 to 4 days of menstrual cycle for PD. ${ }^{21}$

\section{Review of Literature}

Review of literature is an assessment of the entire body of literature as well as critiques of distinctive studies. ${ }^{22}$ Review of literature gives an insight about previous researchers' pros and cons about their study. This helps the present researcher to prepare well in advance to avoid the deficiency in his study. ${ }^{23}$

In the present study, review of literatures is divided into three subheadings

- Studies related to prevalence of dysmenorrhea.

- Studies related to use of contemporary therapies for dysmenorrhea.

- Studies related to effectiveness of ginger on dysmenorrhea.

\section{Literatures Related to Prevalence of Dysmenorrheal}

A study was conducted on female students in Saveetha University to find the burden of dysmenorrhea and menorrhagia. The study results showed that dysmenorrhea was estimated to be $70.4 \%$. Severe dysmenorrhea was present in $9.5 \%$ of girls while 24.6 and $36.5 \%$ experienced moderate and mild dysmenorrhea, respectively.

Although $70.4 \%$ of girls experienced dysmenorrhea, only $3.6 \%$ used pharmacotherapy due to fear of side effects. The study concluded that the burden of dysmenorrhea was found much more than menorrhagia and irregular cycles in their university. They have suggested that dysmenorrhea should be considered a target for reproductive health program. ${ }^{24}$

To study the variations of dysmenorrhea during stress in college going girls, a study was conducted in Belagavi city, Karnataka, India. The prevalence of dysmenorrhea in India varies. It is stated that, in India, prevalence of dysmenorrhea varies from 33 to $79.67 \%$. The study proved that body mass index (BMI) was an independent risk factor among dysmenorrheic girls with the onset of symptoms occurring mostly among the early age group, that is, 20.9 years. The study also proved that there was a positive and significant corelation between each component taken in the Moos Menstrual Distress Questionnaire, with the mean values peaking mostly in the stress group than in the nonstress group. The study concluded that there was a significant variation in dysmenorrhea during stress and nonstress condition in college going girls. ${ }^{25}$

A comprehensive review was performed in the Centre for Longitudinal and Life Course Research, Australia, with large community-based samples to accurately determine the prevalence and risk factors of dysmenorrhea. The study results showed that, the prevalence of dysmenorrhea varies between 16 and $91 \%$ in women of reproductive age, with severe pain in 2 to $29 \%$ of the women studied. Women's age, parity, and use of oral contraceptives were inversely associated with 
dysmenorrhea, and high stress increased the risk of dysmenorrhea. Family history of dysmenorrhea strongly increased its risk. Inconclusive evidence was found for modifiable factors such as cigarette smoking, diet, obesity, depression, and abuse. Dysmenorrhea is a significant symptom for a large proportion of women of reproductive age. This review confirms that dysmenorrhea improves with increased age, parity, and use of oral contraceptives and is positively associated with stress and family history of dysmenorrhea. ${ }^{26}$

A cross-sectional study was performed among 311 undergraduate female students aged 18 to 27 years in Isfahan University of Medical Sciences, Iran, to investigate the prevalence of PD and to determine the factors associated with its intensity. Sociodemographic characteristics and menstrual factors were obtained through interviews with the help of a pretested questionnaire. The prevalence of PD was $89.1 \%$. Residing at home, younger age, lower number of years of formal education for the mother, positive family history of dysmenorrhea, higher severity of bleeding, and shorter menstrual period intervals were significantly associated with the higher intensity of PD. PD is a common health concern among young women. ${ }^{27}$

A cross-sectional descriptive study was conducted in a medical college in Karnataka, India, on 560 female medical students with an objective to evaluate the menstrual characteristics, prevalence, and severity of dysmenorrhea and its effects on the quality of life, particularly absenteeism from college. Three medical colleges in Mangalore (Karnataka, India) were studied. Besides menstrual characteristics, the questionnaire included gradation of pain and quality of life based on the American Chronic Pain Association. Chi-square test and logistic regression were used for statistical analyses. The study showed a significant association of dysmenorrhea with the age of menarche, family history, and both physical and psychological premenstrual symptoms. The most significant conclusion of the study was found to be high prevalence of dysmenorrhea, having a significant effect on the routine activities, and a detrimental effect on the quality of life. The alarming prevalence of self-medication in the form of nonsteroidal anti-inflammatory drugs (NSAIDs), easily available over the counter, was also highlighted in the study. There is a significant association between quality of life and severity of dysmenorrhea. ${ }^{28}$

\section{Literatures Related to Use of Contemporary Therapies for Dysmenorrhea}

A cross-sectional research was conducted in 586 female students at a college in southern Taiwan to determine the affected factors of dysmenorrhea and evaluate the selfperceived efficacy of relief methods. Data was analyzed using a $t$-test, one-way analysis of variance, and Scheffe test. The results showed that traditional Chinese medicine pattern related significantly to dysmenorrhea frequency perception. Using Shenghua decoction, siwu, and pig blood decoction, Angelica drink, ginger, Ziziphus jujube, brown sugar tea, and analgesics all related significantly to dysmenorrhea relief efficacy. Strategies found to help relieve dysmenorrhea level perception include increasing the duration and regularity of sleep and avoiding the consumption of pungent foods. The study suggests that dysmenorrhea-relief courses should be improved in hospitals and schools to assist women to self-manage dysmenorrhea more effectively. ${ }^{29}$

A study for evaluating the efficacy of yoga as an alternative therapy for PD and stress was conducted in Siddhartha Institute of Medical Sciences And Research Foundation, India. Note that 113 medical students, unmarried girls, with PD and stress, were randomly assigned to the study and control group. Semistructured questionnaire, the Numerical Rating Scale for pain, and the Perceived Stress Scale were administered at baseline and after 3 months. The study group was subjected to yoga intervention. The results showed a significant $(p<0.0001)$ reduction in the perceived pain after yoga intervention in the study group. Eighty-eight percent of the study group reported complete pain relief and $12 \%$ reported mild pain, and students with yoga intervention demonstrated significant improvement in perceived stress $(p<0.0001)$. Eighty-two percent of the study group reported complete stress relief. After yoga intervention, absenteeism dropped to $10 \%$ and improvement in daily activity was observed in the study group. The study conclusion was that with yogic exercises stress and pain of dysmenorrhea was controlled indicating the benefits of yoga in PD. Yoga lessens psychosocial stress levels, so it should be implemented among college students to augment their menstrual well-being. ${ }^{30}$

A true experimental research was conducted in a Higher Secondary School at Chrompet, Chennai, India, to assess the effectiveness of acupressure on dysmenorrhea among adolescent girls. Sixty girls who had moderate and severe pain during menstruation and aged between 12 and 16 years who fulfilled the inclusive criteria were divided equally, 30 in the experimental group and 30 in the control group. Probability simple random sampling technique using lottery method was used to select the samples for the experimental and control group. The data analysis revealed that in the experimental group the overall mean difference was 3.2 with standard deviation (SD) of 1.5 and $t$-test value was 11.9 at the level of $p<0.001$. Similarly in the control group, the overall mean difference was 0.1 with SD of 0.5 and $t$-test value was 1.1. It showed statistically significant difference between the experimental and control group. Hence, the acupressure therapy was found to be effective in reducing dysmenorrhea among adolescent girls. ${ }^{31}$

A study was conducted in Puducherry, India, to assess the effect of music therapy during dysmenorrhea in subjects during menstrual phases of menstrual cycle. Thirty young adolescent girls suffering from PD were included in the study. Day 1 of menstrual cycle, a premenstrual syndrome (PMS)-dysmenorrhea questionnaire was administered. Heart rate variability (HRV) was tested for all subjects. Music therapy was administered for 1 week prior to the next expected date of menstruation. Raga Malkauns and Yaman by flute were used for music therapy. Day 1 of next cycle, HRV was repeated and a PMS-dysmenorrhea questionnaire was readministered. The intragroup data was analyzed using paired $t$-test. The results showed that mean dysmenorrhea score before administering music 
therapy was $63.4 \pm 5.3$ compared with postmusic therapy dysmenorrhea score, that is, $57.6 \pm 8.49$. Among HRV parameters, high-frequency domain showed significant difference between pre-MT (music therapy) (42.3 \pm 13 ) and post-MT (50.14 \pm 15.7$)$ with a $p$-value of 0.04 . There was a significant difference in the shift of sympathovagal balance after music therapy toward parasympathetic activity. ${ }^{32}$

A study was conducted in Lucknow, Uttar Pradesh, India, to assess the effect of Yoga Nidra as a treatment in the patients of menstrual disorders with somatoform symptoms. One hundred and fifty female patients with menstrual disorders from the Department of Obstetrics and Gynecology, CSM Medical University (erstwhile KGMU), Lucknow, Uttar Pradesh, India, were randomly divided into two groups: (1) intervention group: 75 subjects (Yoga Nidra intervention and medication) and (2) control group: 75 subjects (without Yoga Nidra intervention, only medication). Schedule for clinical assessment in neuropsychiatry tool was used. There was significant improvement in pain symptoms $(p<0.006)$, gastrointestinal symptoms $(p<0.04)$, cardiovascular symptoms $(p<0.02)$, and urogenital symptoms $(p<0.005)$ after 6 months of Yoga Nidra therapy in the intervention group in comparison to the control group. The results indicate that somatoform symptoms in patients with menstrual disorder can be decreased by learning and applying a program based on yogic intervention (Yoga Nidra). ${ }^{33}$

A study was conducted to assess the beneficial effects of using a far-infrared (FIR) belt on the management of patients with PD in Taiwan. A parallel-arm randomized sham-controlled and double-blinded design with objective physical evidence and psychometric self-reports was used. Fifty-one Taiwanese women with PD were enrolled in the study. Results indicate that there was an increased abdominal temperature of $0.6^{\circ} \mathrm{C}$ and a $3.27 \%$ increase in abdominal blood flow in the FIR group (wearing FIR belt) compared with those in the control group (wearing sham belt). These results demonstrate that the use of a belt made of FIR ceramic materials can reduce $\mathrm{PD}$. $^{34}$

A semiempirical clinical trial was conducted in Iran to assess the effects of massage therapy on endometriosis caused dysmenorrhea. Twenty-three patients suffering from endometriosis were picked as the sample through a simple method. The visual analog scale and McGill questionnaires were used once before and twice after the end of intervention for each patient. The intervention consisted of twenty 20-minute sessions of massage on some specific points of abdomen, sides, and the back (sacrum) of patients. There was a statistically significant difference between the intensity of pain before the intervention started, immediately after, and also 6 weeks after the therapy $(p<0.001)$. According to the results, massage therapy can be a fitting method to reduce the menstrual pain caused by endometriosis. ${ }^{35}$

\section{Literatures Related to Effectiveness of Ginger on Dysmenorrhea}

A study was conducted to assess the effectiveness of ginger tea upon dysmenorrhea among students in Apollo College of
Nursing, Chennai, Tamil Nadu, India. Forty students with dysmenorrhea were selected by purposive sampling technique. Level of dysmenorrhea was assessed in two menstrual cycles. First menstrual cycle was taken as pretest to assess level of dysmenorrhea and the next cycle was posttest in which ginger tea was administered daily as $50 \mathrm{~mL}$ in morning after breakfast and $50 \mathrm{~mL}$ at night after dinner for 5 days starting from 2 days before menstruation. The findings of the study was that before administration of ginger tea the pain level was high (mean $=6.60, \mathrm{SD}=1.59$ ) in comparison with the pain scores of after administering ginger tea (mean $=2.47$, $\mathrm{SD}=1.11$ ). The difference was found to be statistically significant at $p$-value of $<0.001$. The study indicates that nonpharmacological intervention was needed for dysmenorrhea which is a major health problem. ${ }^{36}$ An experimental study was conducted among adolescent girls in Erode, Tamil Nadu, India, to assess the effectiveness of ginger powder on dysmenorrhea. Thirty adolescent girls with dysmenorrhea fulfilling the inclusion criteria were selected. A one-group pretest and posttest pre-experimental design was adopted. A pretest was conducted by using symptoms assessment scale. Immediately after pretest, $1 \mathrm{~g}$ ginger powder was given two times a day for 7 days and posttest was conducted. The results show that the pretest mean score was $65.12(\mathrm{SD}=8.74)$ and posttest mean score was $43.24(\mathrm{SD}=6.72$ ) with paired $t$ value of 23.02, which was significant at 0.01 level.

This showed that ginger was effective. The study implies on the need for educating adolescent girls on effective management of dysmenorrhea. ${ }^{37}$

A study was conducted in Egypt to evaluate the effect of fresh ginger usage as a home remedy on pain relief for dysmenorrhea. A quasi-experimental design was used and using convenient sampling 120 female students were selected. The total number of samples was divided into two equal groups. The first group (control) was instructed not to take anything during menstruation, while the intervention group (60) was instructed to take one table spoon of fresh ginger over $200 \mathrm{~mL}$ warm water by average three cups daily starting 3 days before menstruation and continue use for the first 2 days during menstruation. The results of the study showed that regarding the severity of dysmenorrhea 60\% had moderate dysmenorrhea before intervention which changed into $31.7 \%$ postintervention. In light of this study, importance of use of fresh ginger as a home remedy to relive PD was highlighted. ${ }^{38}$

A quantitative study was performed at Sree Mookambika College of Nursing, Kanyakumari, Tamil Nadu, India, to find out the effectiveness of ginger tea on dysmenorrhea among college students. Nonequivalent pretest-posttest control group design with quantitative evaluative approach was undertaken. Purposive sampling technique was used to select 60 college students with dysmenorrhea, 30 in the experimental group and 30 in the control group. Analyses by descriptive and inferential statistics indicated that the pretest mean value for the experimental group $(7.03 \pm 1.09)$ was almost equal to the control group $(6.96 \pm 1.06)$. The posttest mean value for the experimental group (3.36 \pm 1.54$)$ was less than that of the control group $(6.26 \pm 1.17)$. The mean difference was 3.66. The calculated $t$ value was 15.19 , which 
is higher than the table value of 2.05. There was a significant difference between pre- and posttest values $(p>0.05)$. Hence, ginger tea was found to be effective in reducing dysmenorrhea among the students. ${ }^{39}$

A systematic review done in the United States examined the efficacy of oral ginger for dysmenorrhea. Randomized controlled trials (RCTs) comparing oral ginger against placebo or active treatment in women with dysmenorrhea were included. Six trials were identified. A narrative synthesis of all six studies and exploratory meta-analyses of three studies comparing ginger with placebo and two studies comparing ginger with a NSAID was completed. Ginger appeared more effective in reducing pain severity than placebo. The weighted mean difference on a $10-\mathrm{cm}$ visual analogue scale was $1.55 \mathrm{~cm}$ (favoring ginger) (95\% confidence interval [CI] $0.68-2.43)$. No significant difference was found between ginger and mefenamic acid (an NSAID). The standardized mean difference was 0 ( $95 \% \mathrm{CI}-0.40$ to 0.41 ). Available data suggest that oral ginger could be an effective treatment for menstrual pain in dysmenorrhea. ${ }^{40}$

A quasi-experimental, evaluative research was conducted in Vadodara, Gujarat, India, to compare the effectiveness of dietary ginger versus active exercise on PD among adolescent girls. Using nonprobability convenience sampling, 40 adolescent girls who were in the age group of 17 to 19 years were selected. The tool consisted of section A: demographic tool, B: universal pain assessment tool, C: Menstrual Distress Questionnaire, D: preparation and administration of dietary ginger, and E: preparation and administration of active exercise. Results showed a mean difference in the ginger and exercise groups, which were 5.90 (59\%) and 4.15 (41.5\%), respectively. According to the Menstrual Distress Questionnaire scores, mean difference in both groups were 80.85 (67.4\%) and 69.70 (58.1\%). It proves that dietary ginger is more effective than active exercise. The study concluded that dietary ginger and active exercise both are effective, but dietary ginger appears to be more effective than active exercise on PD. ${ }^{41}$

An RCT was conducted in North Khorasan University of Medical Science, Iran, to compare the effect of ginger, zinc sulfate, and placebo on the severity of PD in young women. One hundred and fifty high school students were recruited. The participants were divided into three groups. The first group received ginger capsules, the second group received zinc sulfate capsules, and the third group received placebo capsules. All participants took the medications for 4 days, from the day before the commencement of menstruation to the third day of their menstrual bleeding. The severity of dysmenorrhea was assessed every 24 hours by the pain visual analog scale. The severity of pain was significantly different between, before, and after the intervention in both the ginger and the zinc sulfate groups $(p<0.001)$. Compared with the placebo receiving group, participants receiving ginger and zinc sulfate reported more alleviation of pain during the intervention $(p<0.05)$. Ginger and zinc sulfate had similar positive effects on the improvement of PD pain in young women. ${ }^{42}$

\section{Conceptual Framework}

A conceptual framework is an interpretive grid with several variations and contexts. It is used to make conceptual distinctions and organize ideas in an easier way. A wellbuilt conceptual framework projects something real and it explains the relation between key factors, concepts, or variables which are associated with the subject. A conceptual model broadly grants an apprehension of the phenomenon of interests and mirrors the assumptions and philosophical views of the model's designer. ${ }^{43}$

Conceptual models are usually a diagrammatic or graphic illustration of interpretations or concepts which are systematically arranged in virtue of their relevance to the theme. The conceptual framework used in this study is the modification of Karl Ludwig von Bertalanffy's general system theory. ${ }^{44}$

\section{Statement of the Problem}

Effectiveness of ginger tea on dysmenorrhea among the nursing students in a selected nursing college at Mangaluru.

\section{Objectives}

- To assess the level of dysmenorrhea among nursing students.

- To determine the effectiveness of ginger tea on dysmenorrhea among nursing students.

- To find the association between level of dysmenorrhea before the administration of ginger tea and demographic variables.

\section{Hypotheses}

The following hypothesis will be tested at 0.05 level of significance:

$\mathrm{H}_{1}$ : There will be significant difference in level of pain after the intervention.

$\mathrm{H}_{2}$ : There will be a significant difference in level of pain between the experimental and control groups after the intervention.

$\mathrm{H}_{3}$ : There will be a significant association between dysmenorrhea before the treatment and selected baseline variables.

\section{Methods}

Methodology explains the various means and tactics used to execute data collection. It comprises the theoretical analysis of the body of methods and principles associated with a branch of knowledge. ${ }^{45}$

\section{Research Approach}

A quantitative research approach was taken up in this study. The researcher evaluated the effect of ginger tea on reducing dysmenorrhea during menstruation in a group of nursing 
students. To find out the effect, ginger tea was prepared and administered to the subjects by the researcher and the effect was analyzed by comparing the mean of baseline aspects of pain using pain quality assessment scale and the mean after administration of the drink for four times.

\section{Research Design}

It explains the overall plan specifying the methods and procedures for collecting and analyzing the needed data in a research study. ${ }^{45}$ In this study, quasi-experimental design was adopted to find out the effect of ginger tea on dysmenorrhea among nursing students in a selected nursing college hostel at Mangaluru.

The study was conducted in a selected nursing college girl's hostel at Mangaluru, named NUINS Nursing College hostel at Paneer. The setting was ideal for the availability of samples that are homogeneous, and was feasible for conducting the research. Hence, researcher selected the particular setting.

Accessible populations were the students with moderate or severe dysmenorrhea who met the inclusion criteria. The sample consists of 50 nursing students who has moderate or severe pain during menstruation and who is residing in the selected nursing college hostel.

\section{Variables}

Variables are attributes such as qualities, quantities, properties, or characteristics of people, things, or situations that change or vary. ${ }^{46}$

Independent variable: Variables that are deliberately manipulated by the researcher is independent variables. ${ }^{46}$ In this study, ginger tea is the independent variable.

Dependent variable: Variables that change as the independent variable is molded by the researcher. It is sometimes called the criterion variables. ${ }^{46}$ In this study, dysmenorrhea level after the administration of ginger tea is the dependent variable.

\section{Sampling Technique}

Sampling is the method of choosing a cluster of the population to represent the gross population. ${ }^{14}$ Purposive sampling technique was used in this study. It is a nonprobability sampling method in which the researcher selects participants based on personal judgment about which ones will be most informative; sometimes called judgmental sampling. ${ }^{14}$

Fifty nursing students who met the inclusion criteria were selected. They were then allocated to the experimental group and control group conveniently by the researcher. In this method, the researcher makes use of his knowledge and chooses samples according to his convenience.

After the pilot study, the research proposal was found to be feasible, and hence the main study was performed. Ethical clearance was also obtained. Permission for carrying out the study was obtained from the concerned authorities of NUINS college and the hostel warden. The subjects were selected based on the inclusion criteria and were explained about the procedure.

Subject information sheet was explained and handed over to the subjects. During the data collection period, ginger tea was prepared by the researcher and $120 \mathrm{~mL}$ was administered on the first 2 days of menstruation in the morning and night after breakfast and dinner, respectively, to the subjects.

Level of different aspects of pain was assessed before the administration as well as 2 hours after administration of ginger tea using the Pain Quality Assessment Scale. Pretest and posttest were taken before as well as 2 hours after administering the drink. A total of four doses were given and ratings were measured eight times.

\section{Results}

For this study, 50 participants were identified based on the inclusion and exclusion criteria. From each subject, demographic characteristics, clinical characteristics, and baseline pain and different characteristics of pain were measured. Purposive sampling technique was used to select the samples. They were divided equally into experimental (25) and control (25) group. Intervention was given only to the experimental group. The collected information was analyzed, summarized, and presented (-Tables 1-3).

\section{Ginger Tea Experience Shared by the Participants}

The responses given by the experimental and control groups were mentioned separately. Ginger tea effects and experience were verbalized for the experimental group alone.

The associated physical symptoms and premenstrual symptoms mentioned by the participants were severe back pain, leg pain, body pain, stomach pain, inflammation, severe abdominal pain, weakness, nausea and vomiting, giddiness, fatigue, radiating leg pain, pain in back and thighs, pimples, constipation, and pain in nipples and breast.

Emotional changes were short temper, irritation, and sadness. Social behaviors included sensitivity to touch. Psychological symptoms were depression, short temper, and getting disturbed very fast, and social behaviors were feeling to be alone, talk minimum, unable to concentrate, and do not feel to go out.

The ginger tea experience shared by the participants in the experimental group were relaxation, feel of freshness, no need for other measures of pain relief, spicy taste, and able to perform activities. This information developed at the time of data collection supported the statistical finding of the study that ginger is effective in reducing dysmenorrhea.

This finding was supported by another study conducted by Aziato et al. The onset and duration of pain was varied and the intensity of pain was severe. Pain was associated with several other signs and symptoms such as headache, diarrhea, anorexia, and nausea and vomiting.

This study also aimed to explore the effects of dysmenorrhea on participants. It was realized that dysmenorrhea led to activity intolerance, and severe pain resulted in absenteeism 
Table 1 Distribution of sample characteristics between experimental and control groups

\begin{tabular}{|c|c|c|c|c|c|c|}
\hline \multirow[t]{2}{*}{ Characteristics } & \multirow[t]{2}{*}{ Groups } & \multirow[t]{2}{*}{ Mean } & \multirow[t]{2}{*}{ SD } & Mean difference & \multirow[t]{2}{*}{$t$} & \multirow{2}{*}{$\begin{array}{l}n=50 \\
p \text {-Value }\end{array}$} \\
\hline & & & & $(95 \% \mathrm{Cl})$ & & \\
\hline \multirow[t]{2}{*}{ Age } & Experimental & 19.60 & 1.414 & \multirow[t]{2}{*}{$1.52(0.941-2.01)$} & \multirow[t]{2}{*}{5.274} & \multirow[t]{2}{*}{$<0.001^{*}$} \\
\hline & Control & 18.08 & 0.277 & & & \\
\hline \multirow[t]{2}{*}{ Height $(\mathrm{cm})$} & Experimental & 156 & 4.86 & \multirow[t]{2}{*}{$-0.640(-3.22$ to 1.94$)$} & \multirow[t]{2}{*}{-0.499} & \multirow[t]{2}{*}{0.620} \\
\hline & Control & 157 & 4.18 & & & \\
\hline \multirow[t]{2}{*}{ Weight $(\mathrm{kg})$} & Experimental & 49.36 & 5.24 & \multirow[t]{2}{*}{$-0.640(-3.364$ to 2.084$)$} & \multirow[t]{2}{*}{-0.472} & \multirow[t]{2}{*}{0.639} \\
\hline & Control & 50 & 4.29 & & & \\
\hline \multirow[t]{2}{*}{ Age at menarche $(y)$} & Experimental & 13.04 & 1.241 & \multirow[t]{2}{*}{$0.280(-0.384$ to 0.944$)$} & \multirow[t]{2}{*}{0.847} & \multirow[t]{2}{*}{0.401} \\
\hline & Control & 12.76 & 1.091 & & & \\
\hline \multirow[t]{2}{*}{$\begin{array}{l}\text { Duration of menstrua- } \\
\text { tion }(d)\end{array}$} & Experimental & 5.0 & 1.080 & \multirow[t]{2}{*}{$-0.280(-0.878$ to 0.318$)$} & \multirow[t]{2}{*}{0.942} & \multirow[t]{2}{*}{0.351} \\
\hline & Control & 5.28 & 1.021 & & & \\
\hline \multirow[t]{2}{*}{ Interval of cycle (d) } & Experimental & 29.52 & 1.388 & \multirow[t]{2}{*}{$0.440(-0.496$ to 1.376$)$} & \multirow[t]{2}{*}{0.945} & \multirow[t]{2}{*}{0.349} \\
\hline & Control & 29.08 & 1.869 & & & \\
\hline \multirow[t]{2}{*}{ Duration of pain (d) } & Experimental & 2.68 & 0.557 & \multirow[t]{2}{*}{$0.400(0.110-0.690)$} & \multirow[t]{2}{*}{2.774} & \multirow[t]{2}{*}{$0.008^{*}$} \\
\hline & Control & 2.68 & 0.458 & & & \\
\hline
\end{tabular}

Abbreviations: $\mathrm{Cl}$, confidence interval; SD, standard deviation.

Note: The table shows that the calculated $t$ value for characteristics such as "age" and "duration of pain" is more than the table value, which is 2.014 at $5 \%$ level of significance. Also, the $p$-value for these characteristics is $<0.05$. This shows that there is a significant difference in age and duration of pain between experimental and control groups. For all other comparisons, the $p$-value is $>0.05$ and the calculated values are less than the $t$ table value (2.014) which shows there was no difference in these characters between experimental and control groups.

Table 2 Comparison of pain between the experimental and control groups by using Mann-Whitney $U$ test $(n=50)$

\begin{tabular}{|c|c|c|c|c|c|}
\hline & & \multirow[t]{2}{*}{$Z$} & Morning & \multirow[t]{2}{*}{$Z$} & Night \\
\hline & & & $p$-Value & & $p$-Value \\
\hline \multirow[t]{2}{*}{ Intensity } & Day 1 & -3.101 & $0.002^{\mathrm{a}}$ & -4.244 & $<0.001^{\mathrm{a}}$ \\
\hline & Day 2 & -3.838 & $<0.001^{\mathrm{a}}$ & -4.677 & $<0.001^{\mathrm{a}}$ \\
\hline \multirow[t]{2}{*}{ Sharpness } & Day 1 & -3.072 & $0.002^{\mathrm{a}}$ & -4.478 & $<0.001^{a}$ \\
\hline & Day 2 & -4.636 & $<0.001^{\mathrm{a}}$ & -4.548 & $<0.001^{\mathrm{a}}$ \\
\hline \multirow[t]{2}{*}{ Hot } & Day 1 & -2.996 & $0.003^{a}$ & -3.911 & $<0.001^{a}$ \\
\hline & Day 2 & -4.075 & $<0.001^{\mathrm{a}}$ & -3.660 & $<0.001^{\mathrm{a}}$ \\
\hline \multirow[t]{2}{*}{ Numbness } & Day 1 & -3.632 & $<0.001^{\mathrm{a}}$ & -4.088 & $<0.001^{a}$ \\
\hline & Day 2 & -4.035 & $<0.001^{\mathrm{a}}$ & -4.349 & $<0.001^{\mathrm{a}}$ \\
\hline \multirow[t]{2}{*}{ Cramping } & Day 1 & -3.819 & $<0.001^{\mathrm{a}}$ & -4.164 & $<0.001^{\mathrm{a}}$ \\
\hline & Day 2 & -4.466 & $<0.001^{\mathrm{a}}$ & -4.506 & $<0.001^{\mathrm{a}}$ \\
\hline \multirow[t]{2}{*}{ Radiating } & Day 1 & -3.758 & $<0.001^{\mathrm{a}}$ & -3.884 & $<0.001^{\mathrm{a}}$ \\
\hline & Day 2 & -3.884 & $<0.001^{\mathrm{a}}$ & -4.496 & $<0.001^{\mathrm{a}}$ \\
\hline \multirow[t]{2}{*}{ Unpleasant } & Day 1 & -4.120 & $<0.001^{\mathrm{a}}$ & -4.740 & $<0.001^{\mathrm{a}}$ \\
\hline & Day 2 & -4.693 & $<0.001^{\mathrm{a}}$ & -4.435 & $<0.001^{\mathrm{a}}$ \\
\hline
\end{tabular}

Note: Mann-Whitney $U$ test was used to identify the effectiveness of intervention between experimental and control groups in each measurements of pain. Table above shows that the posttest $p$-values for both the days of interventions of various pain characteristics, namely intensity, sharpness, hot, numbness, cramping, radiating, and unpleasant are less than the 0.05 level of significance. Hence, it is concluded that there was a significant difference between the groups after the intervention. This shows that ginger tea is effective in relieving dysmenorrhea. Hence, the research hypothesis $\mathrm{H} 1$ is accepted.

alndicates significance. 
Table 3 Comparison of pain between the pre- and post-values of experimental and control groups by using Wilcoxon signedrank test $(n=50)$

\begin{tabular}{|c|c|c|c|c|c|c|c|c|c|}
\hline & & \multicolumn{4}{|c|}{ Experimental } & \multicolumn{4}{|c|}{ Control } \\
\hline & & \multicolumn{2}{|c|}{ Morning } & \multicolumn{2}{|l|}{ Night } & \multicolumn{2}{|l|}{ Morning } & \multicolumn{2}{|l|}{ Night } \\
\hline & & $Z$ & $p$-Value & $Z$ & $p$-Value & $Z$ & $p$-Value & $Z$ & $p$-Value \\
\hline \multirow[t]{2}{*}{ Intensity } & Day 1 & -4.117 & $<0.001^{a}$ & -4.309 & $<0.001^{\mathrm{a}}$ & -2.246 & $0.025^{\mathrm{a}}$ & -1.006 & 0.314 \\
\hline & Day 2 & -4.360 & $<0.001^{\mathrm{a}}$ & -4.360 & $<0.001^{\mathrm{a}}$ & -2.714 & $0.007^{a}$ & -0.302 & 0.763 \\
\hline \multirow[t]{2}{*}{ Sharpness } & Day 1 & -4.392 & $<0.001^{a}$ & -4.414 & $<0.001^{a}$ & -3.066 & $0.002^{\mathrm{a}}$ & -1.185 & 0.236 \\
\hline & Day 2 & -4.408 & $<0.001^{a}$ & -4.417 & $<0.001^{a}$ & -0.302 & 0.763 & -0.905 & 0.366 \\
\hline \multirow[t]{2}{*}{ Hot } & Day 1 & -4.031 & $<0.001^{\mathrm{a}}$ & -4.038 & $<0.001^{a}$ & -2.654 & $0.008^{\mathrm{a}}$ & -2.111 & $0.035^{\mathrm{a}}$ \\
\hline & Day 2 & -4.036 & $<0.001^{\mathrm{a}}$ & -4.080 & $<0.001^{a}$ & -0.690 & 0.490 & -1.642 & 0.101 \\
\hline \multirow[t]{2}{*}{ Numbness } & Day 1 & -3.938 & $<0.001^{a}$ & -4.038 & $<0.001^{a}$ & -1.945 & 0.052 & -1.081 & 0.279 \\
\hline & Day 2 & -4.055 & $<0.001^{a}$ & -4.086 & $<0.001^{\mathrm{a}}$ & -1.134 & 0.257 & -0.707 & 0.480 \\
\hline \multirow[t]{2}{*}{ Cramping } & Day 1 & -4.303 & $<0.001^{a}$ & -4.315 & $<0.001^{a}$ & -2.066 & $0.039^{a}$ & -1.508 & 0.132 \\
\hline & Day 2 & -4.278 & $<0.001^{a}$ & -4.260 & $<0.001^{a}$ & -0.632 & 0.527 & -0.333 & 0.739 \\
\hline \multirow[t]{2}{*}{ Radiating } & Day 1 & -4.211 & $<0.001^{\mathrm{a}}$ & -4.223 & $<0.001^{\mathrm{a}}$ & -2.919 & $0.004^{\mathrm{a}}$ & -1.897 & 0.058 \\
\hline & Day 2 & -4.229 & $<0.001^{a}$ & -4.220 & $<0.001^{a}$ & -2.178 & 0.029 & -0.302 & 0.763 \\
\hline \multirow[t]{2}{*}{ Unpleasant } & Day 1 & -4.385 & $<0.001^{a}$ & -4.411 & $<0.001^{a}$ & -1.814 & 0.070 & -0.544 & 0.957 \\
\hline & Day 2 & -4.400 & $<0.001^{\mathrm{a}}$ & -4.408 & $<0.001^{\mathrm{a}}$ & $<0.001$ & 1.0 & -0.741 & 0.458 \\
\hline
\end{tabular}

Note: This table identifies statistically the difference in pain before and after the intervention in the experimental and control groups separately. From the above table it is clear that $p$-values for various pain characteristics in the experimental group is $<0.05$ for 2 days of morning and night interventions. Hence, there was a significant difference in these measurements before and after the administration of ginger tea. Whereas $p$-value is found to be $>0.05$ for pain characteristics in majority of the subjects in the control group, except for day 1 morning measurement of radiating, cramping, sharpness, both the days morning measurement of intensity, and day 1 morning and night measurement of hot. It indicates that ginger tea was effective in reducing menstrual pain.

andicates significance.

from work and school. It resulted in reduced work output and inattentiveness in class. The sufferers became moody, irritable, and were not able to interact effectively with other people. The pain contributed to sleeplessness and restlessness. ${ }^{47}$

\section{Discussion}

\section{Major Findings of the Study}

Description of Demographic and Clinical Characteristics The participants' age ranged between 18 and 24 years (mean $18.84 \pm 1.27)$. The height $(\mathrm{cm})$ of the participants was within the range of 149 to $169 \mathrm{~cm}$ with a mean height of $157.24 \pm 4.5 \mathrm{~cm}$.

The mean weight of the participants was $49.68 \pm 4.75 \mathrm{~kg}$, with $39 \mathrm{~kg}$ being the minimum weight and $59 \mathrm{~kg}$ was the maximum weight.

Nursing students had a minimum BMI value of $15.62 \mathrm{~kg} / \mathrm{m}^{2}$ and a maximum value of $25.78 \mathrm{~kg} / \mathrm{m}^{2}$, with a mean of $20.20 \mathrm{~kg} / \mathrm{m}^{2} \pm 2.5$.

Minimum age at which menarche was attained is 11 years and maximum was 15 years, with a mean age of 12.9 years \pm 1.17. Nursing students had minimum of 3 days of menstruation and maximum of 7 days, mean $5.14 \pm 1.05$.

Minimum of 25 days of menstruation and maximum of 32 days, with mean of $29.3 \pm 1.65$, was the interval of cycle of menstrual period in nursing students.
The above findings were supported by a study conducted by Naik et al which had average age of all the participants as $20.9 \pm 1.8$ years. In the study, the average mean height of participants was $159.9 \pm 7.0 \mathrm{~cm}$ and mean weight was $55.03 \pm 9.7 \mathrm{~kg}$ and the BMI of participants in various courses was $21.4 \pm 3.5 \mathrm{~kg} / \mathrm{m}^{2} .^{25}$ The results are almost similar to the current study's demographic characteristics with regard to age, height, weight, and BMI.

Another study done by Charu et al also had similar demographic characters. The average age of the participants was $20.57 \pm 1.208$ years (ranging from 17 to 24 years) and the mean BMI of the participants was $21.69 \pm 3.27 \mathrm{~kg} / \mathrm{m}^{2}$ (ranging from 14.7 to $33.54 \mathrm{~kg} / \mathrm{m}^{2}$ ). Regarding menstrual characteristics, the average age of menarche was $12.67 \pm 1.10$ years (9-16 years) and the average interval of menstrual cycle of the participants in the study group was $29.52 \pm 3.37$ days. ${ }^{28}$ The result supports the current study findings.

In context to the duration of menstruation, the participants had minimum of 3 days of menstruation and maximum of 7 days, with a mean of $5.14 \pm 1.05$ days. This finding was supported by findings of Kavuluru, which says majority of the adolescent girls, that is, $36.6 \%$ have 96 hours, followed by $30 \%$ having 48 hours, followed by $25 \%$ having 72 hours, and least number, that is, $8.3 \%$ adolescent girls, having 120 hours and above duration of menses. ${ }^{48}$ 
Distribution of Level of Pain Experienced by Nursing

\section{Students Using Descriptive Statistics}

In the present study, 50 participants were selected who were having moderate and severe pain based on numerical pain rating scale. Among them most of the participants 34 (68\%) had severe pain. Rest of them had moderate pain 16 (32\%). Majority of the participants who had severe pain belonged to the experimental 18 (36\%) and control group16 (32\%).

This result was supported by another study conducted by Latha and colleagues which stated that in the pretest majority of participants in the experimental and control groups had severe pain 56.67 and 53.33\%, respectively, and the rest of them had moderate pain (experimental group $43.33 \%$ and control group 46.67\%). ${ }^{39}$

In contrast, a descriptive study conducted in four residential schools of Udupi district to identify dysmenorrhea, characteristics, and associated symptoms showed that majority had moderate pain77 (33\%), 41 (17.6\%) had severe pain, and $28(12 \%)$ had mild pain out of 233 samples, during menstruation. ${ }^{49}$

The participants had experienced several symptoms associated with menstruation other than dysmenorrhea. Fatigue was seen in majority of the participants 35 (70\%), 19 (38\%) had headache which was the next common symptom. Nausea and vomiting was seen in 16 (32\%) participants, followed by diarrhea occurrence in 14 (28\%) of the nursing students.

Fainting 13 (26\%) and dizziness 10 (20\%) was the next frequently occurring symptoms. Insomnia was seen in $9(18 \%)$ participants, constipation in 6 (12\%), and disorientation only in $1(2 \%)$ subject. Hypersensitivity to sound was experienced by 14 (28), light by 9 (18\%), touch by $7(14 \%)$, and smell by $5(10 \%)$ nursing students. Other symptoms that was identified were back pain 3 (6\%) and appearance of pimples $3(6 \%)$. Body pain, breast tenderness, leg pain, and urinary infection were the other symptoms which occurred in single participants respectively 1 (2\%).

The above findings were supported by another study conducted by Singh et al from India, which explained that the participants suffering from dysmenorrhea $(n=79)$, presented with following symptoms, that is, backache (62.0\%), headache (26.58\%), fatigue (70.88\%), and vomiting/diarrhea (6.32\%). In 107 participants, 60.74\% were presented with PMS, symptoms consisted of: breast heaviness (17.75\%), abdominal bloating (12.14\%), backache $(25.23 \%)$, headache (13.08\%), uneasiness (22.42\%), and anxiety (8.41\%). ${ }^{50}$

All of the above findings are consistent with El-Gilany et al's study which says that the most frequent symptoms associated with dysmenorrhea were fatigue, headache, backache, dizziness, and anorexia/vomiting. ${ }^{51}$

\section{Distribution of Associated Symptoms}

The participants had experienced several symptoms associated with menstruation other than dysmenorrhea. Fatigue was seen in majority of the participants 35 (70\%), 19 (38\%) had headache which was the next common symptom. Nausea and vomiting was seen in 16 (32\%) participants, followed by diarrhea occurrence in 14 (28\%) of the nursing students. Wilcoxon signed-rank test showed that there was a significant difference in pain measurements before and after the administration of ginger tea $(p<0.05)$. These findings indicate that ginger tea was effective in reducing menstrual pain.

The findings stated above were supported by another study conducted among adolescent girls in Erode to assess the effectiveness of ginger powder on dysmenorrhea. The results showed that the pretest mean score was 65.12 $(\mathrm{SD}=8.74)$ and the posttest mean score was $43.24(\mathrm{SD}=6.72)$ with paired $t$ value of 23.02, which was significant at 0.01 level. This showed that ginger was effective. ${ }^{37}$

A similar study conducted in Apollo College of Nursing proved that before administration of ginger tea the pain level was high (mean $=6.60, \mathrm{SD}=1.59$ ) in comparison with the pain scores after administering ginger tea (mean $=2.47$, $\mathrm{SD}=1.11$ ). The difference was found to be statistically significant at $p<0.001$ level of confidence. The study indicates that nonpharmacological intervention was needed for dysmenorrhea which is a major health problem. ${ }^{36}$

At the international level, a systematic review done in the United States examined the efficacy of oral ginger for dysmenorrhea. RCTs comparing oral ginger against placebo or active treatment in women with dysmenorrhea were included. The results proved that ginger appeared to be more effective for reducing pain severity than placebo. Available data suggest that oral ginger could be an effective treatment for menstrual pain in dysmenorrhea. The present study findings along with literature review indicate that ginger has got a positive effect in reducing dysmenorrhea. ${ }^{40}$

\section{Association between Baselines Pain with Selected Demographic Variables}

The findings suggested that demographic as well as clinical variables have no association with baseline pain (dysmenorrhea before treatment).The $p$-value was $>0.05$ (at $5 \%$ level of significance) for all the variables which clearly explains that there is no association between baseline dysmenorrhea and demographic variables.

This finding was supported by another similar study conducted by Kavuluru to assess the effect of ginger preparation in dysmenorrhea which revealed that there was no significant association between preinterventional and postinterventional dysmenorrhea with selected demographic variables at $p(0.05)$ level of significance. ${ }^{48}$

Similar findings were seen in a study by Rahnama et al who conducted a RCT of ginger capsules in the treatment of PD. This study results showed that there was no association of pretest and posttest dysmenorrhea with baseline characteristics at $p<0.05$ level of significance. ${ }^{52}$

\section{Conclusion}

Pain is a natural mechanism of the body. It is unavoidable in most of the conditions. But the severity of pain can be reduced with appropriate interventions. The world is moving more toward natural therapies to cope up with pain. Dysmenorrhea is one such type of pain, which is inevitable, but with appropriate interventions can be reduced to an extent. 
The awareness about alternative therapies such as ginger which can reduce the pain without much adverse effects on body systems must be elucidated.

\section{References}

1 Proctor ML, Murphy PA. Herbal and dietary therapies for primary and secondary dysmenorrhoea. Cochrane Database Syst Rev 2001;3:CD002124

2 Eisenberg DM, Davis RB, Ettner SL, et al. Trends in alternative medicine use in the United States, 1990-1997: results of a follow-up national survey. JAMA 1998;280(18):1569-1575

3 Lloyd KB, Hornsby LB. Complementary and alternative medications for women's health issues. Nutr Clin Pract 2009;24(5):589-608

410 Health Benefits of Ginger Root - The Wonder Spice [Internet]. Isha Sadhguru. 2015. Available at: https://isha.sadhguru. org/in/en/wisdom/article/10-ways-ginger-root-of-well-being. Accessed July 18, 2019

5 Menstruation. In: Wikipedia [Internet]. 2017. Available at: https://en.wikipedia.org/w/index.php?title=Menstruation\&oldid=770387166. Accessed July 18, 2019

6 Kural M, Noor NN, Pandit D, Joshi T, Patil A. Menstrual characteristics and prevalence of dysmenorrhea in college going girls. J Family Med Prim Care 2015;4(3):426-431

7 Dawood MY. Primary dysmenorrhea: advances in pathogenesis and management. Obstet Gynecol 2006;108(2):428-441

8 Smith RP, Kaunitz AM. Primary dysmenorrhea in adult women: clinical features and diagnosis - UpToDate [Internet]. UpToDate. Available at: https://www.uptodate.com/contents/primary-dysmenorrhea-in-adult-women-clinical-features-and-diagnosis?search=Pathogenesis,\%20clinical\%20 manifestations,\%20and\%20diagnosis\%20of\%20primary\%20 dysmenorrhea\%20in\%20adult\%20women\&source=search_ result\&selectedTitle=1 150. Accessed March 9, 2017

9 Doty E, Attaran M. Managing primary dysmenorrhea. J Pediatr Adolesc Gynecol 2006;19(5):341-344

10 Bettendorf B, Shay S, Tu F. Dysmenorrhea: contemporary perspectives. Obstet Gynecol Surv 2008;63(9):597-603

11 What is the rate of incidence for dysmenorrhea? | Dysmenorrhea (Painful Periods) [Internet]. Sharecare. Available at: https://www.sharecare.com/health/painful-periods/rate-of-incidence-for-dysmenorrhea, Accessed July 18, 2018

12 Lowdermilk DL, Perry SE, Bobak IM. Maternity and Women's Health Care. Missouri, St. Louis: Mosby, Incorporated; 1997: $269 \mathrm{p}$

13 Home remedies for dysmenorrhoea organic facts. Available at: https://www.organic facts.net/home-remedies for dysmenorrhea. Accessed March 22, 2017

1411 Proven Health Benefits of Ginger [Internet]. Healthline. Available at: https://www.healthline.com/nutrition/11proven-benefits-of-ginger. Accessed March 22, 2017

15 Ayu D. Pain during menstruation or dysmenorrhea occurs in 50 [Internet]. Scribd. Available at: https://www.scribd. com/document/333846133/Pain-during-menstruation-ordysmenorrhea-occurs-in-50-docx. Accessed March 23, 2017

16 Nair P, Grover VL, Kannan AT. Awareness and practices of menstruation and pubertal changes amongst unmarried female adolescents in a rural area of East Delhi Indian. J Comm Med 2007;32(2):156</jrn>

17 Sheila W, Malathy K, Premila S. Menstrual and gynaecological disorders in 500 school girls in Madras city. J Obstet Gynaecol India 1993;43:940-945</jrn>

18 Omidvar S, Begum K. Menstrual pattern among unmarried women from south India. J Nat Sci Biol Med 2011;2(2):174-179

19 Unsal A, Ayranci U, Tozun M, Arslan G, Calik E. Prevalence of dysmenorrhea and its effect on quality of life among a group of female university students. Ups J Med Sci 2010;115(2):138-145

20 Tseng Y-F, Chen C-H, Yang Y-H. Rose tea for relief of primary dysmenorrhea in adolescents: a randomized controlled trial in Taiwan. J Midwifery Womens Health 2005;50(5):e51-e57

21 Marian MJ, Integrative Nutrition Therapy MDGM. South Asia: CRC Press; 2015:498 p

22 Polit DF, Beck CT. Nursing Research: Generating and Assessing Evidence for Nursing Practice. 9th ed. Philadelphia: Lippincott Williams \& Wilkins; 2013:827 p

23 Polit DF, Hungler BP. Nursing Research: Principles and Methods. 6th ed. Philadelphia: Lippincott Williams \& Wilkins; 2000

24 Sharma N, Sagayaraj MB, Sujatha B, et al. Prevalence of dysmenorrhoea in college students. Int J Scientific Res Publ 2014;4(10):1-6

25 Naik P, Tanna AS, Mudaliar PN, Tari AD. Variations of dysmenorrhea during stress and non stress condition in college going girls in Belgaum City: a cross sectional study. IJPR 2015;3(2):1012-1016

$26 \mathrm{Ju}$ H, Jones M, Mishra G. The prevalence and risk factors of dysmenorrhea. Epidemiol Rev 2014;36(1):104-113

27 Habibi N, Huang MSL, Gan WY, Zulida R, Safavi SM. Prevalence of primary dysmenorrhea and factors associated with its intensity among undergraduate students: a cross-sectional study. Pain Manag Nurs 2015;16(6):855-861

28 Charu S, Amita R, Sujoy R, Thomas GA. 'Menstrual characteristics' and 'prevalence and effect of dysmenorrhea' on quality of life of medical students. Public Health 2012;4(4):278-294

29 Chen CX, Barrett B, Kwekkeboom KL. Efficacy of oral ginger (Zingiber officinale) for dysmenorrhea: a systematic review and meta-analysis. Evid Based Complement Alternat Med 2016;2016:6295737

30 Nag U, Dip P, Kodali M. Effect of yoga on primary dysmenorrhea and stress in medical students. IOSR JDMS 2013;4(1):69-73

31 Elakkiya C. An experimental study to assess the effectiveness of acupressure on dysmenorrhea among adolescent girls in Hilton Matriculation Higher Secondary School at Chrompet, Chennai. Int J Innov Res Dev 2015;4(1):8-10

32 Kushalappa JA, Lakshmanagowda PB. Effect of music therapy in dysmennorhic subjects during menstrual phase of menstrual cycle. Semantic Scholar 2014;5(12):748-750

33 Daily JW, Zhang X, Kim DS, Park S. Efficacy of ginger for alleviating the symptoms of primary dysmenorrhea: a systematic review and meta-analysis of randomized clinical trials. Pain Med 2015;16(12):2243-2255

34 Ke Y-M, Ou M-C, Ho C-K, Lin Y-S, Liu H-Y, Chang W-A. Effects of somatothermal far-infrared ray on primary dysmenorrhea: a pilot study. Evid Based Complement Alternat Med 2012;2012:240314

35 Valiani M, Ghasemi N, Bahadoran P, Heshmat R. The effects of massage therapy on dysmenorrhea caused by endometriosis. Iran J Nurs Midwifery Res 2010;15(4):167-171

36 Dhanya S, Shobana G, Latha V. Effectiveness of ginger tea for dysmenorrhea. J Trained Nurs Assoc India 2012;7(2):23-29

37 Padmavathi P, Sankar DR, Kokilavani DN. A Study to assess the effectiveness of ginger powder on dysmenorrhoea among adolescents in a selected school at Erode. Asian J Nurs Educ Res 2012;2(2):79-82

38 Awed H, El-Saidy T, Amro T. The use of fresh ginger herbs as a home remedy to relieve primary dysmenorrhea. J Res Nurs Midwifery 2013;2(8):104-113

39 Latha S, Venketesan DL. Effectiveness of ginger tea on dysmenorrhea among college students International. J Appl Res 2016;2(12):669-671

40 Chen C-K, Huang Y-P, Fang H-L, Huang Y-Y. Dysmenorrhea: a study of affected factors and approaches to relief among female students at a college in southern Taiwan [in Chinese]. Hu Li Za Zhi 2013;60(3):40-50 
41 Trivedi H, Koshy S. Effectiveness of dietary ginger v/s active exercise on primary dysmenorrhea among adolescent girls. Int J Innov Res Dev 2016;5(6):35-40

42 Kashefi F, Khajehei M, Tabatabaeichehr M, Alavinia M, Asili J. Comparison of the effect of ginger and zinc sulfate on primary dysmenorrhea: a placebo-controlled randomized trial. Pain Manag Nurs 2014;15(4):826-833

43 Polit DF, Hungler BP. Nursing Research: Principles and Methods. 6th ed. Philadelphia: Lippincott; 2000

44 Berman AT, Snyder S, Frandsen G. Kozier \& Erb's Fundamentals of Nursing. 9th ed. Philadelphia: Elsevier; 2010

45 Magher M. What Is the Meaning of Conceptual Framework in Research [Internet] Classroom. Available at: https:// classroom.synonym.com/meaning-conceptual-framework-research-6664512.html. Accessed February 29, 2016

46 NB. (PhD) Grove SK. Understanding Nursing Research: Building an Evidence-based Practice. 4th ed. New Delhi: Saunders Elsevier; 2007:586 p

47 Aziato L, Dedey F, Clegg-Lamptey JNA. The experience of dysmenorrhoea among Ghanaian senior high and university students: pain characteristics and effects. Reprod Health 2014;11:58

48 Kavuluru VP. A study to assess the effectiveness of ginger preparation on dysmenorrhea among adolescent girls International. J Appl Res 2017;3(3):22-25

49 George NS, Priyadarshini S, Shetty S. Dysmenorrhoea among adolescent girls - characteristics and symptoms experienced during menstruation. Nitte Univ J Health Sci 2014;4(3):45-52

50 Singh A, Kiran D, Singh H, Nel B, Singh P, Tiwari P. Prevalence and severity of dysmenorrhea: a problem related to menstruation, among first and second year female medical students. Indian J Physiol Pharmacol 2008;52(4):389-397

51 El-Gilany AH, Badawi K, El-Fedawy S. Epidemiology of dysmenorrhoea among adolescent students in Mansoura, Egypt. East Mediterr Health J 2005;11(1-2):155-163

52 Rahnama P, Montazeri A, Huseini HF, Kianbakht S, Naseri M. Effect of Zingiber officinale R. rhizomes (ginger) on pain relief in primary dysmenorrhea: a placebo randomized trial. BMC Complement Altern Med 2012;12(1):92 